\title{
The CFD analysis of influence the start of fuel injection (SOI) on combustion parameters and exhaust gas composition of the marine 4-stroke engine
}

\begin{abstract}
The paper presents a theoretical analysis of the impact of injection timing on the parameters of the combustion process and the composition of exhaust gas from a 4-stroke engine designed to shipbuilding. The analysis was carried out based on a three-dimensional multi-zone model of the combustion process. This model has been prepared on the basis of properties of the research facility. The input data to the model were obtained through laboratory tests. Results of calculations showed that the change of the start of injection angle (SOI) from the value of 14 degrees before TDC to 22 degrees before TDC results in changes in the combustion rate and thus an increase in the temperature of the combustion process as well as the increase of nitric oxides fraction in the exhaust gas. Simultaneously the maximum combustion pressure increases also.
\end{abstract}

Key words: marine 4-stroke engine, $\mathrm{NO}_{x}$ emission, CFD model, combustion, SOI

\section{Introduction}

Diesel engines are still irreplaceable source of mechanical energy in heavy vehicles and ships. For this reason the research work to improve the efficiency of this kind of machines are important and continued. Generally the improve of Diesel engines efficiency may be done by increasing the share of energy taken from the fuel combustion to moving the piston, recovery the energy from the exhaust gas or the decreasing of cooling the engine. All presented ways may be improved by the regulation of the combustion process in the engine cylinder. Mentioned regulation is usually conducted by modification of fuel injection process. Properly prepared combustion mixture in the engine cylinder has crucial role in the combustion process. It should be noted that fuel injected into the cylinder is broken-up, evaporated and mixed with air in quick and turbulent process. The auto ignition is occur in the cylinder area and time in which is proper pressure, temperature and composition of mixture. According to this the start of fuel injection (SOI) beside the fuel spray geometry is significant for improving the engine efficiency and decreasing the emission of toxic combustion products into the atmosphere.

Researches on the influence of SOI value on parameters and the emission from Diesel engines are commonly presented in the literature. Both methods i.e. the decreasing of the engine cooling and SOI changes strategy are presented in [7]. Authors tested the 6 cylinder LHR (Low Heat Rejection) engine. The effect of LHR was prepared by ceramic coating the cylinder. The thermal efficiency was increased from $28-36 \%$ to $35-41 \%$ but the side effect is the increase of the nitric oxides $\left(\mathrm{NO}_{\mathrm{x}}\right)$ emission at high speed and load due to the increase of the combustion temperature. The method of the $\mathrm{NO}_{\mathrm{x}}$ emission decreasing is the delay of fuel injection. Authors changes the SOI angle from original $20^{\circ}$ before top dead center of the piston position (BTDC) to $18^{\circ}$ and $16^{\circ}$. The result of this regulation was decreasing of $\mathrm{NO}_{\mathrm{x}}$ emission and a little decreasing of brake specific fuel consumption (BSFC) for high load and all considered speeds for $18^{\circ}$ BTDC. Further reduction of the SOI angle causes the decrease of $\mathrm{NO}_{\mathrm{x}}$ emission but rapid increase of BSFC. In the opposition to this result are observations presented in [11]. Authors of this research present results for the small, single cylinder, diesel engine with common rail system and the range of the SOI from 40 to 0 degrees BTDC. According to presented results the decrease of the SOI causes the decrease of indicated specific fuel consumption. Similar to [7] results are presented in [8]. Some optimal SOI value is observed in another type of the engine (naturally aspirated, single-cylinder, 4-stroke, direct injection). It should be noted that use biodiesel blend of fossil diesel oil and fish oil changes this optimal value of the SOI, but changing of the engine compression ratio not influence on the optimal for BSFC SOI value [12]. The change of optimal value of SOI is observed for ceiba pentandra biodiesel [16]. This optimal value of SOI was not observed for diesel-propane blends on the range of SOI from 19 to 15 degrees BTDC [21], diesel canola oil methyl ester blends (SOI 15, 20, 25) [3] and castor diesel blends (SOI 25, 23, 21) [1]. The possible reason of this fact is too small range of SOI. The largest range of tested SOI is presented in [2] (from 50 to 10 degrees BTDC). Authors of this research present results of model and laboratory tests. According to presented results the maximum $\mathrm{NO}_{\mathrm{x}}$ emission was observed for SOI equals 30 degrees BTDC and the increase and the decrease of the SOI causes the decrease of $\mathrm{NO}_{\mathrm{x}}$ emission. Higher range of the SOI was presented in [18]. Authors present laboratory test results for small $\left(498 \mathrm{~cm}^{3}\right)$ single cylinder, diesel engine with common-rail system and the range of the SOI from 200 to 50 degrees BTDC. This dramatically increase of the SOI causes decrease of in-cylinder pressure and heat release rate (HRR). The high reduction of $\mathrm{NO}_{\mathrm{x}}$ content in the exhaust gas is observed but the increase of the SOI over the 80 degrees BTDC not changes of this value. Authors stated that minimum content of $\mathrm{NO}_{\mathrm{x}}$ is observed for $6.5 \mathrm{~ms}$ of ignition delay independently from the engine speed and the value of compression ratio. According to [5] combination of the SOI changing strategy with exhaust gas recirculation EGR causes the decrease of $\mathrm{NO}_{\mathrm{x}}$ emission and the increase of BSFC. The decrease of $\mathrm{NO}_{\mathrm{x}}$ content in the exhaust gas is observed for multi injection strategies also [10]. The increase of the SOI for first pulse of fuel injection decreases the $\mathrm{NO}_{\mathrm{x}}$ content and increases the BSFC for single, duo and triple strategy of injection for diesel blends with coconut oil biodiesel (B20 and B50). 
Less attention is paid for modeling aspect of this phenomena. Work [15] present the CFD model of combustion for diesel engine as a segment of cylinder volume, corresponding with one hole of fuel nozzle and results of exhaust gas composition for different SOI. Rakopoulos et al. [17] present simple two-zone model of combustion for the SOI and the EGR investigations. Both research present similar results for $\mathrm{NO}_{\mathrm{x}}$ content in exhaust gas.

This short review of literature show that investigations on influence of the SOI are intensive but some shortcomings may be observed. It should be noted that most research are done for small engines on the basis of the laboratory research. There are only a few works about CFD modeling of this aspect. According to this the research target of this work is the CFD analysis of influence the value of the SOI of the large marine engine parameters and exhaust gas composition.

\section{Materials and methods}

The research object is 3 cylinder, 4 stroke, turbocharged and intercooled Diesel engine to marine applications. The cylinder bore equals $250 \mathrm{~mm}$ and $350 \mathrm{~mm}$ of the cylinder stroke. During the tests the engine was operated at constant speed equals $750 \mathrm{rpm}$ and constant load equals $250 \mathrm{~kW}$ measured as an electric power on the generator. This type of engine is commonly used in the marine applications as a propulsion of electric power generators or main propulsion of relatively small vessels. Parameters of the research object and the measurement equipment as well as the scheme of the laboratory test stand and fuel properties were presented in [13]. The fuel nozzle consists of 9 holes with $0.325 \mathrm{~mm}$ of diameter and 158 degrees of holes angle. The data collected during the laboratory test was used to prepare and validate the CFD model of combustion in the engine cylinder. Model is prepared on the base of the moving 3D mesh of the combustion chamber with the inlet and outlet ducts and cylinder valves. Model consists of the fuel injection and brake-up model on the basis of WAVE mechanism [9] with the Wakisaka modification [20], the Dukowicz fuel evaporation model [6]. The 3Z-ECFM [4] model of combustion process was chosen. This model allows to the autoignition point calculation also. Model is developed by the heat transfer and turbulent flow models. Closer parameters of the model and its validation was presented in [14]. During laboratory tests the engine was operated with the SOI equals 18 degrees BTDC and delayed SOI to 13.5 degrees BTDC also. The model, presented in [14] was validated for fuel injection delaying also. Prepared model for delayed SOI calculates maximum combustion pressure (pick pressure) with $6.2 \%$ error and mean combustion pressure with $2.8 \%$ error. The calculation errors for oxygen and $\mathrm{NO}_{\mathrm{x}}$ fractions in the exhaust gas equals $3.2 \%$ and $9.2 \%$ respectively. Mentioned model was used to calculate parameters of the combustion process in the engine cylinder and the composition of the exhaust gas. During the calculation the SOI was changed as follows: 22, 20, 18, 16 and 14 degrees BTDC.

\section{Results and discussion}

The delaying of the SOI value is commonly used method to reduction $\mathrm{NO}_{\mathrm{x}}$ emission from Diesel engines. Left side of Figure 1 presents the mass of fuel evaporated to the engine cylinder. The delay of fuel injection causes evident move the evaporation function to the expansion stroke direction but it should be noted that at the early stage of evaporation the quantity of evaporated mass increases. For example the $0.2 \mathrm{~g}$ of evaporated fuel mass is reached at $9.2^{\circ}$ of crankshaft after SOI 22deg BTDC and only $7.9^{\circ}$ of crankshaft for SOI 14deg BTDC.
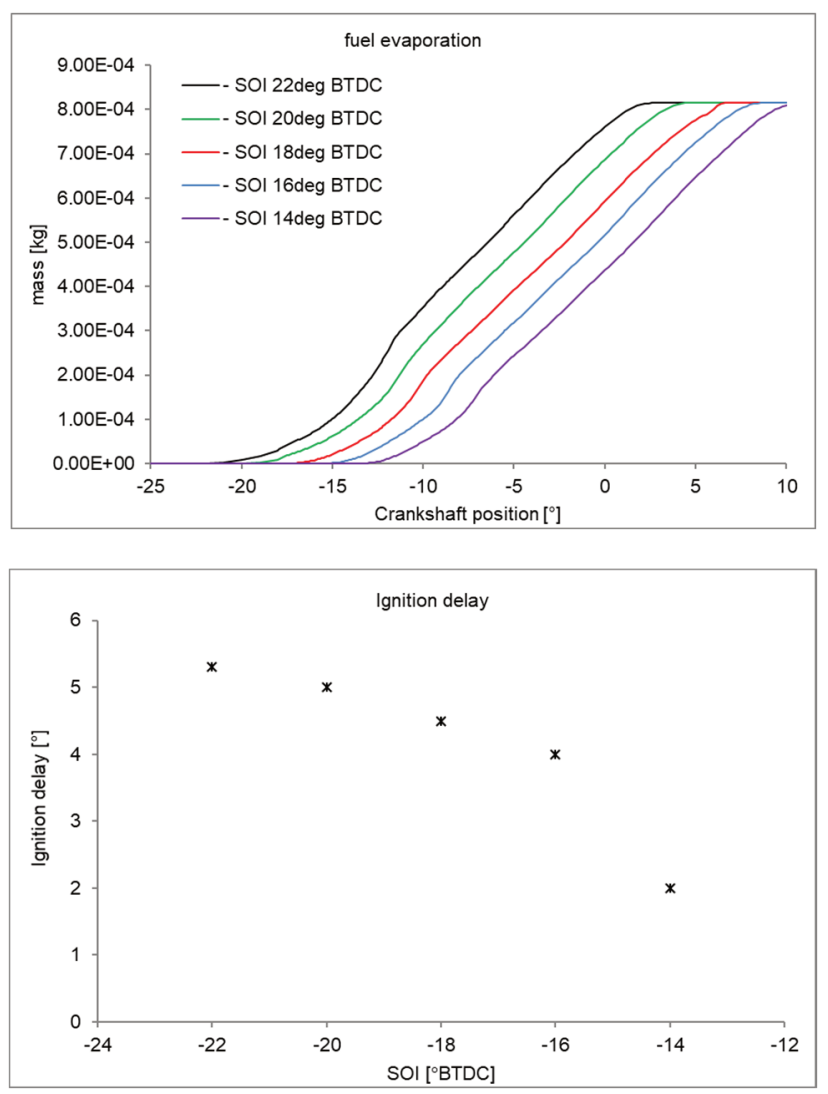

Fig. 1. Fuel mass evaporation and ignition delay

The effect of this is shortening the auto ignition delay from $5.3^{\circ}$ for SOI $22 \mathrm{deg}$ BTDC to $2.0^{\circ}$ for SOI $14 \mathrm{deg}$ BTDC. The right side of the Figure 1 presents this dependence. It means that the position of auto ignition point depends mainly on the thermodynamic parameters in the combustion chamber than combustion mixture. The delay of the SOI causes decreasing of the intensity of combustion during the early stage (kinetic chemistry controlled combustion). It should be noted that this stage of combustion is responsible for the maximum temperature of combustion. The dependence of the heat release rate (HRR) is presented on the left side of Figure 2. Simultaneously with the decrease of the intensity of the kinetic stage of combustion the diffusion stage of combustion decreases also, but the maximum HRR for diffusion stage of combustion is higher than maximum HRR for kinetic stage. The delaying of SOI causes increasing time of combustion also. The low temperature heat release rate [19] for the beginning of combustion is practically not visible at all considered calculations. Right side of Figure 2 presents the time of combustion of 5, 10,50 and 90 percent of fuel. The increase of the time of 
combustion with delaying the SOI is observed for all phases of combustion.
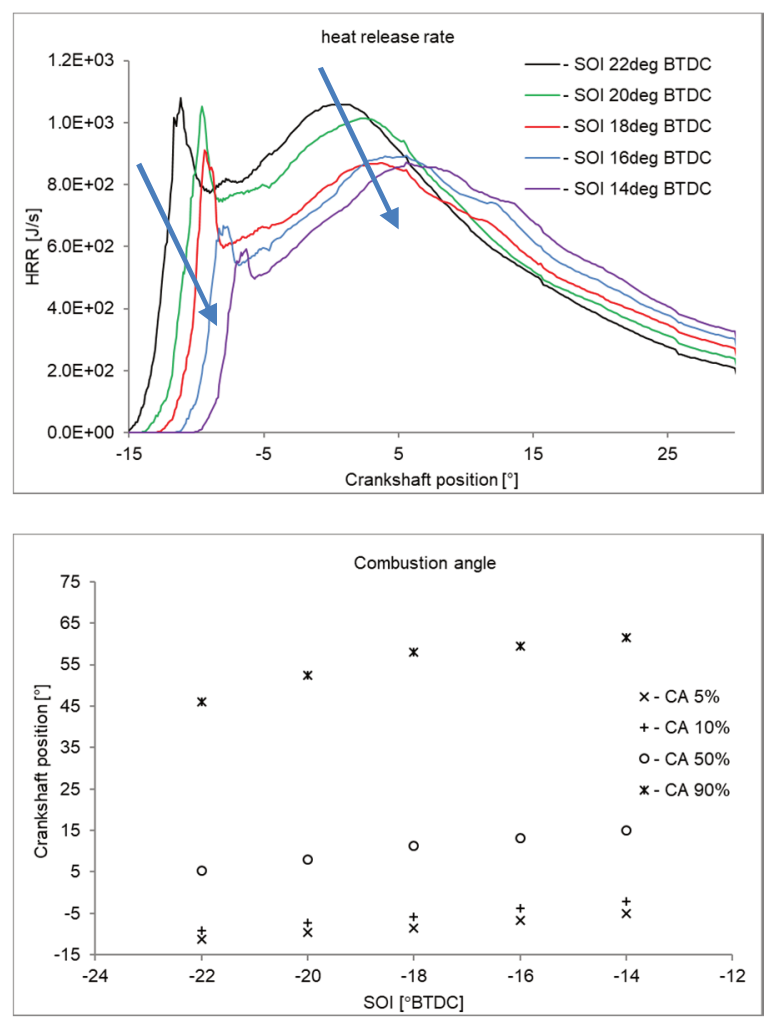

Figure 3 and 4 present the HRR (calculated as a mean value for the overall combustion chamber volume) rate in the cross section of the combustion chamber as well as the velocity of the combustion mixture at 12 degrees of the crankshaft position after the SOI. According presented results the increase of the angle of the SOI causes the decrease of intensity of combustion near the fuel nozzle and the increase of the combustion intensity on the front of the fuel spray. This phenomenon is confirmed by results of velocity calculation (Fig. 4). The area with maximum values of the velocity is closer to the fuel nozzle for high values of the SOI.

The intensity of the combustion process may be asses by the observation of fractions of unburned fractions of the combustion mixture. Figure 5 presents fractions of hydrogen $(\mathrm{H})$ and carbon monoxide $(\mathrm{CO})$. According to presented results $\mathrm{H}$ fraction rapidly increase in the initial stage of combustion for the early SOI. It should be considered that hydrogen is dominant precursor of combustion process. It means that high rate of the hydrogen content causes intense combustion and increase of the pressure and temperature of combustion due to low activation energy of the chemical reaction of this species. The right side of the Figure 5 present fraction of $\mathrm{CO}$ in the combustion chamber. According this point of view the combustion process is slower for the delaying of the SOI, but the $\mathrm{CO}$ fraction in the combustion chamber is larger at the end of combustion process.

Fig. 2. The heat release rate and the combustion characteristics

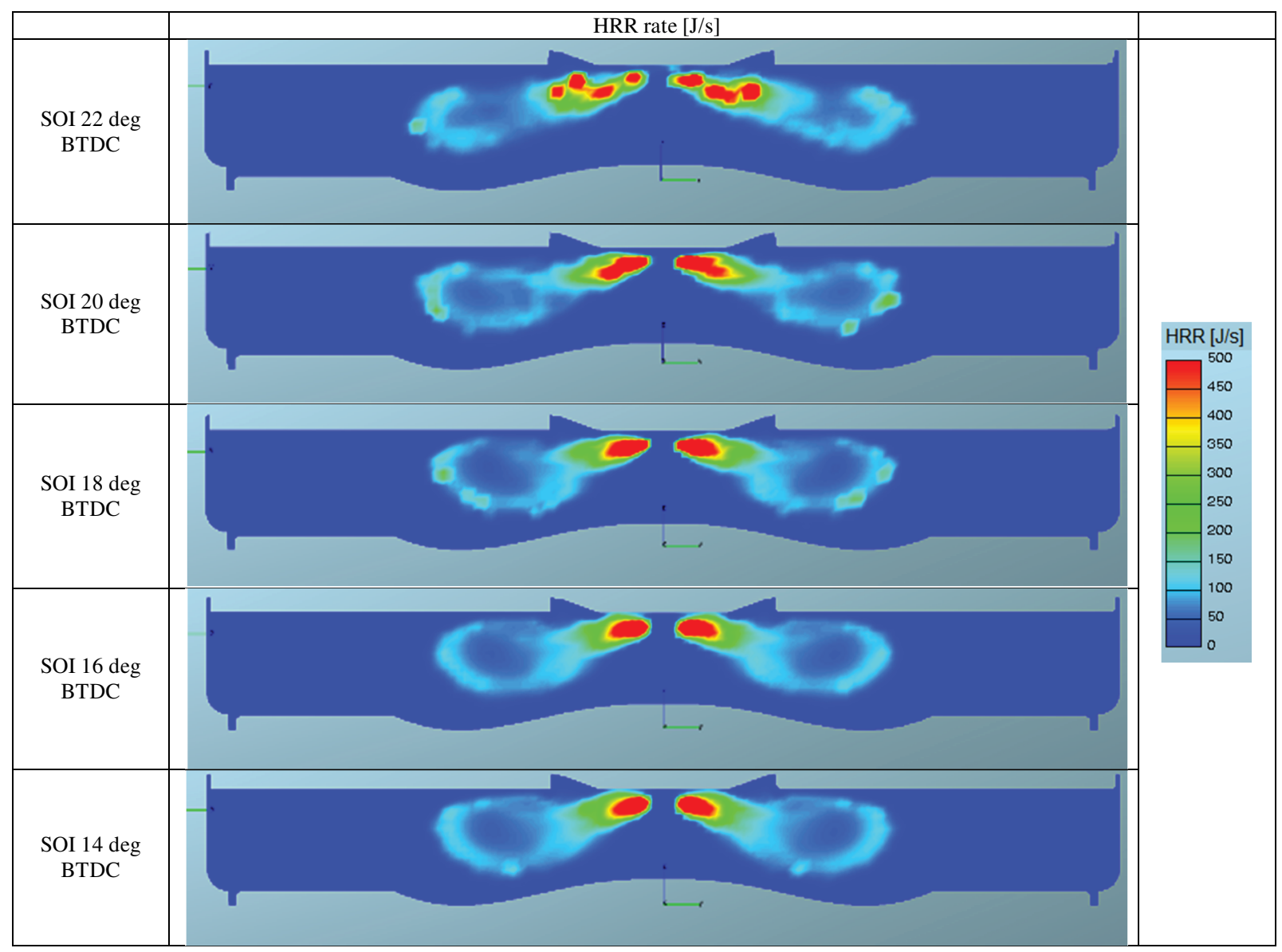

Fig. 3. Heat release rate distribution in the combustion chamber at 12 degrees of the crankshaft position after the SOI 
The increase of kinetic stage of combustion causes the increase of the maximum temperature of combustion because the combustion process is rapid. It happens for large values of the SOI. According to results presented in the Figure 6 , the delaying of the SOI by 8 degrees causes the decrease of the maximum temperature in the combustion chamber (calculated as a mean temperature of overall cylinder volume) of almost $200 \mathrm{~K}$. Changes in the start of the combustion are clearly visible in the Figure 6 also. It should be noted that the prolongation of the combustion process with the delaying of the SOI do not change the temperature of combustion at the end of the combustion process.

The delaying of the SOI causes the decrease of the maximum combustion pressure (pick pressure). The left side of Figure 7 present dependences of the combustion pressure and values of the SOI. According to presented results considered changes of the SOI causes the change of pick pressure by $2 \mathrm{MPa}$. A little delaying of the pick pressure position is observed also (less than 2 degrees of the crankshaft position).
The right side of the Figure 7 presents values of pick pressure and the mean indication pressure (MIP) for all considered SOI. According to presented results visible changes of the pick pressure values not influence on the visible change of the MIP value. Considered changes of the SOI cause only $0.25 \mathrm{MPa}$ change of MIP. The explanation of this phenomena is the decrease of the value of the pick pressure and simultaneously increase of the time of combustion. It means that the combustion process is slower and smooth. On the other hand the decrease of MIP and increase of the CO fraction at the end of the combustion process clearly proves the decrease of the combustion efficiency. It is important that presented results come from calculations. It means that the quantity of injected fuel and delivered air are not changed. The deterioration of the combustion process at constant load of the engine cause increase of the fuel dose injected to the cylinder and change the cooperation the engine with turbocharger due to the engine speed governor operation. Result of this is increase of MIP to the value enough to keep constant engine speed at current load.

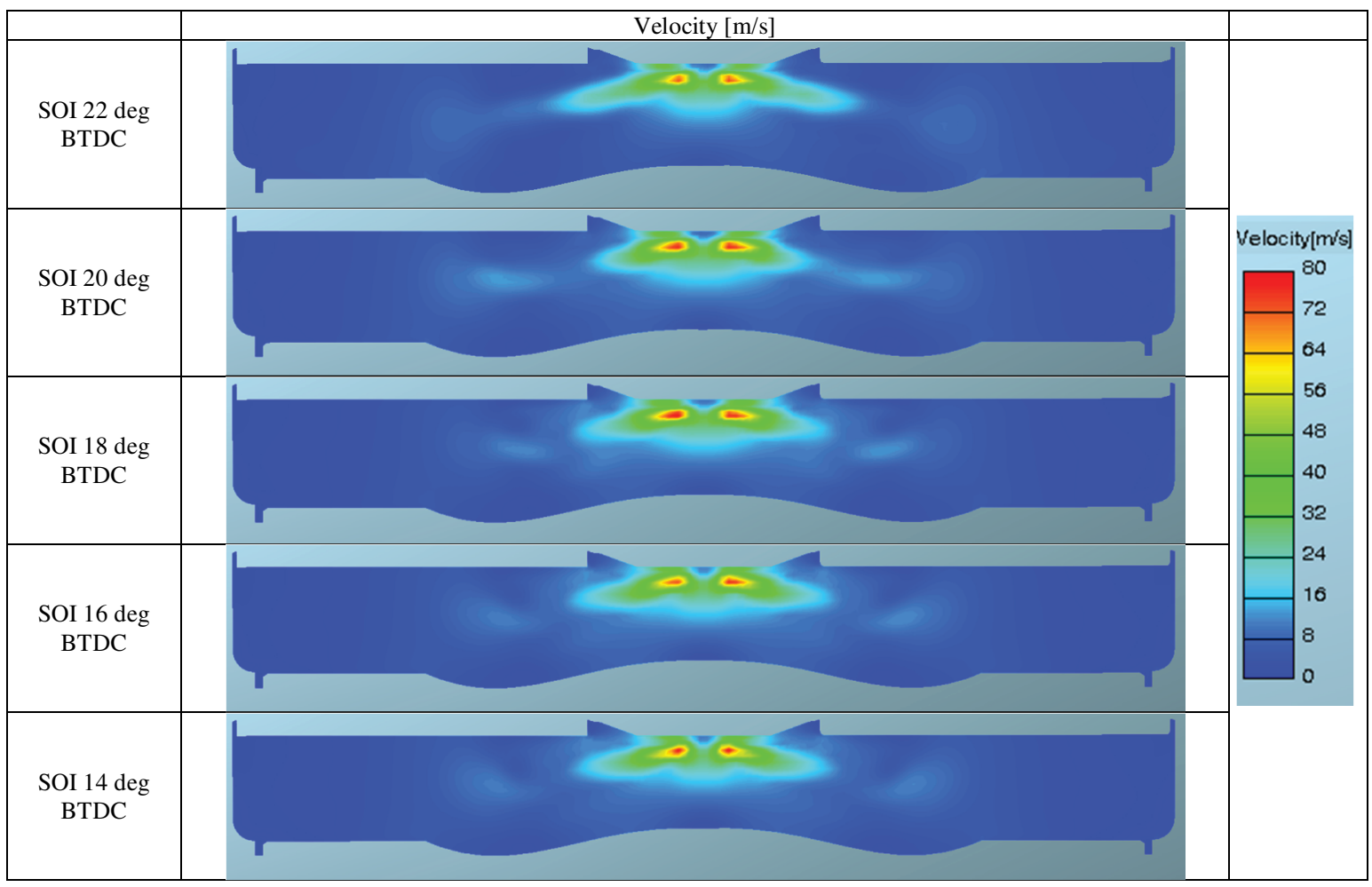

Fig. 4. Velocity distribution of gases in the combustion chamber at 12 degrees of the crankshaft position after the SOI
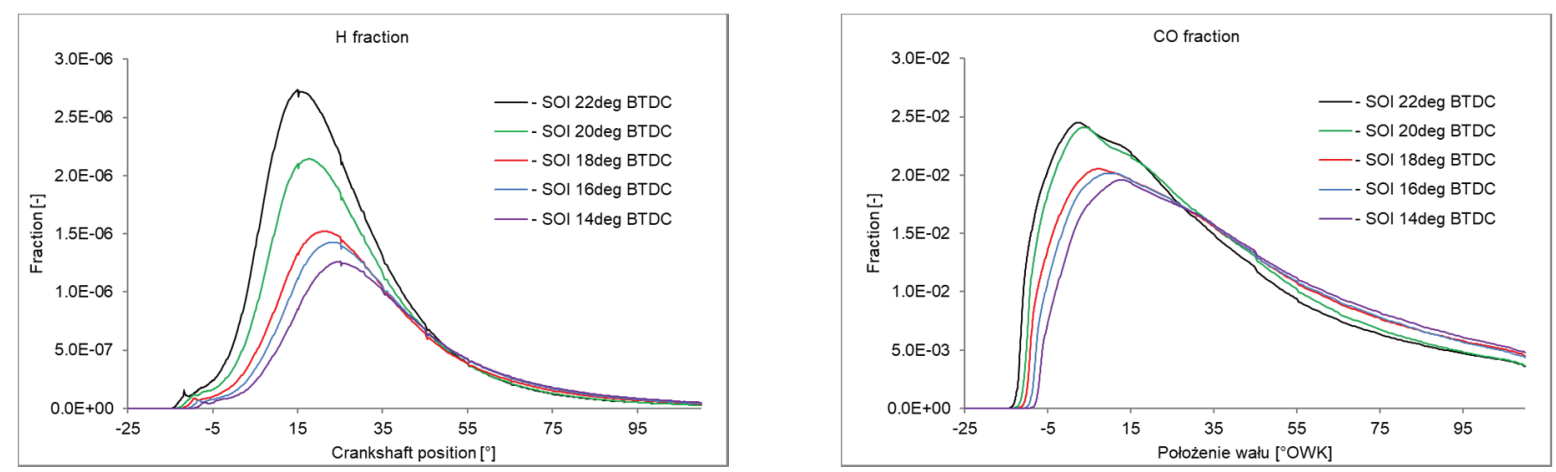

Fig. 5. Hydrogen and carbon monoxide fraction in the combustion chamber 
The lower temperature of combustion and the slower combustion process contribute to the decrease of nitric oxides $\left(\mathrm{NO}_{\mathrm{x}}\right)$ fraction in the combustion chamber and the consequently in the exhaust gas. This phenomenon is presented in the Figure 8. The $\mathrm{NO}_{\mathrm{x}}$ fraction is calculated as a sum of the nitric oxide and the nitric dioxide in this model. It should be noted that model of $\mathrm{NO}_{\mathrm{x}}$ formation consisted of thermal and prompt mechanisms with NO oxidation [14]. Considered delaying of the SOI causes decrease of the $\mathrm{NO}_{\mathrm{x}}$ fraction in the combustion chamber at the end of the combustion process from $1760 \mathrm{ppm}$ to $520 \mathrm{ppm}$. This trend is expected but the scale of $\mathrm{NO}_{\mathrm{x}}$ decreasing is high.

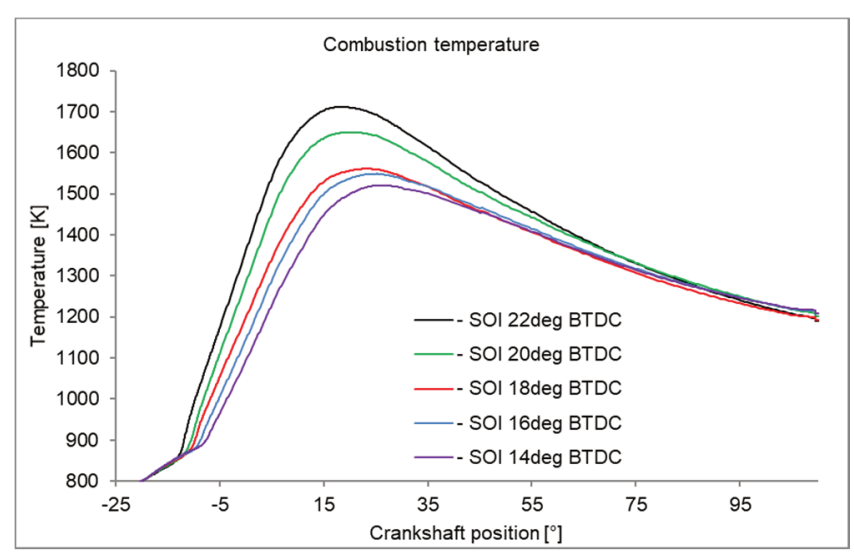

Fig. 6. Temperature of the combustion process
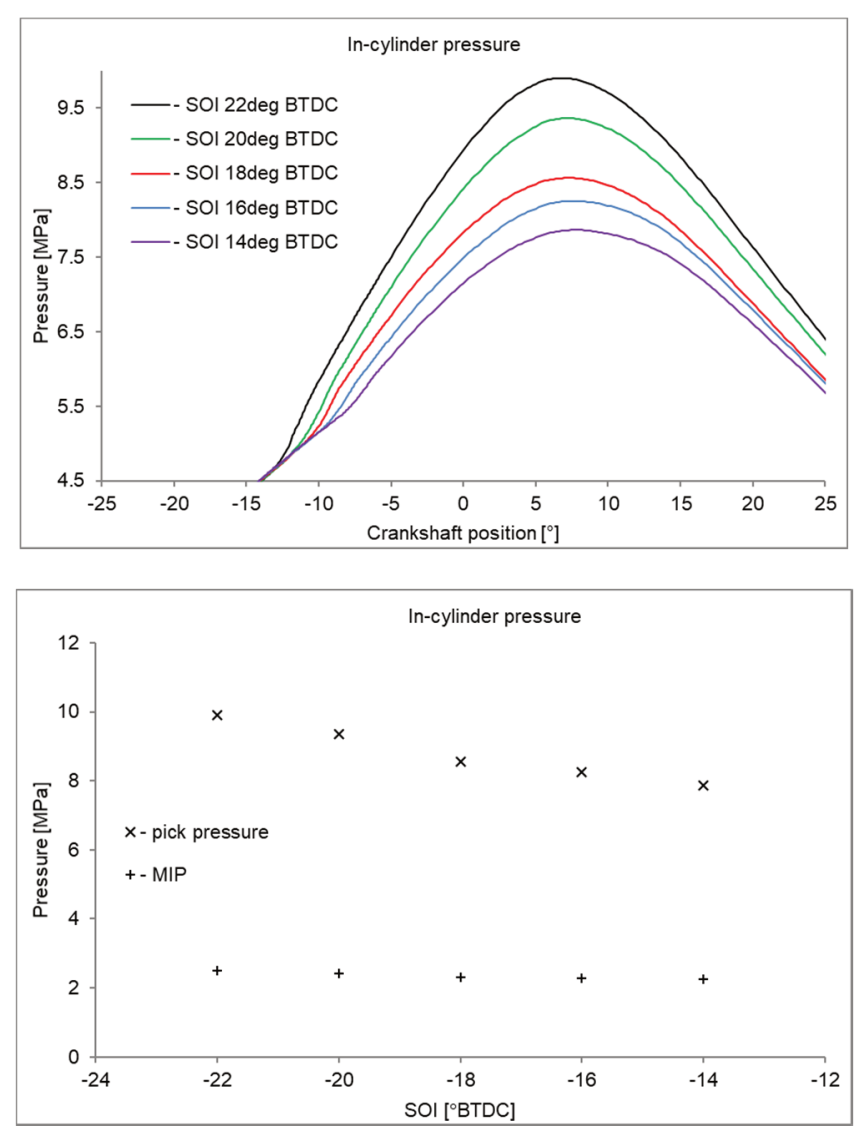

Fig. 7. Pressure of combustion

\section{Conclusions}

The work presents the influence of the SOI on parameters of the combustion process and the exhaust gas composition in the marine 4-stroke Diesel engine. The analysis is based on the three dimension CFD calculations on the model validated for real laboratory stand. On the basis of presented results following conclusions has been made:

- The delay of fuel injection causes the increase of the evaporated mass of fuel at the early stage of evaporation.

- Thermodynamic parameters in the combustion chamber causes that the shortening of the auto ignition delay is observed also.

- After auto ignition the quantity of evaporated fuel is biggest near the fuel nozzle and the kinetic stage of combustion in less intensive.

- Simultaneously with the decrease of the intensity of the kinetic stage of combustion the diffusion stage of combustion decreases also, but the maximum HRR for diffusion stage of combustion is higher than maximum HRR for kinetic stage.

- The delaying of SOI simultaneously causes increasing time of combustion due to decrease of both stages of combustion.

- The decrease of the SOI angle causes the increase of intensity of combustion near the fuel nozzle and the decrease of the combustion intensity on the front of the fuel spray. This phenomenon is confirmed by results of velocity calculation. The area with maximum values of the velocity is closer to the fuel nozzle for high values of SOI.

- Result of this is the decrease of the maximum combustion pressure as well as the maximum combustion temperature.

- Delaying the SOI causes the decrease of the $\mathrm{NO}_{\mathrm{x}}$ fraction and the increase of $\mathrm{CO}$ fraction at the end of combustion.

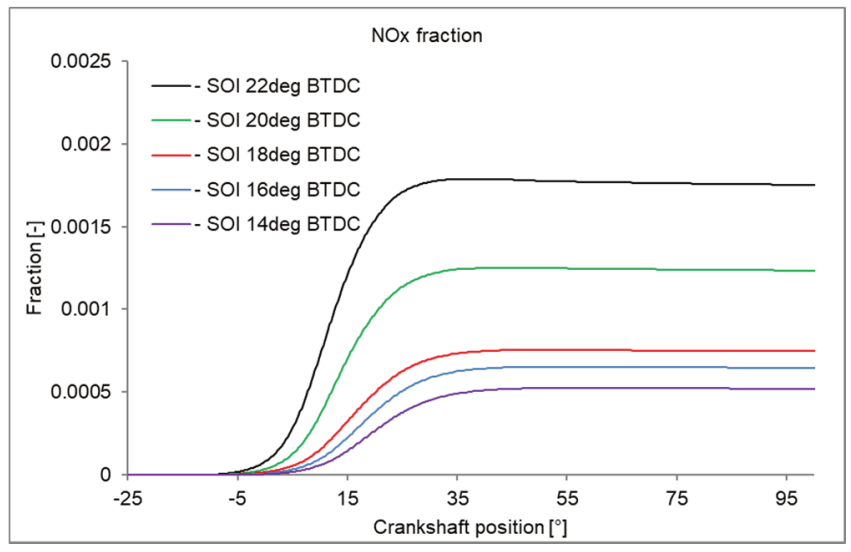

Fig. 8. Nitric oxides fraction in the combustion chamber

\section{Acknowledgements}

The project was supported by AVL Company according to University Partnership Program and license of AVL Fire software. 


\section{Bibliography}

[1] BUYUKKAYA, E., CERIT, M. Experimental study of NO emissions and injection timing of a low heat rejection diesel engine. Int. J. Therm. Sci. 2008, 47(8), 1096-1106, DOI: 10.1016/j.ijthermalsci.2007.07.009.

[2] COLIN, O., BENKEIDA, A. The 3-Zones Extended Coherent Flame Model (ECFM3Z) for computing premixed/diffusion combustion. Oil \& Gas Science and Technology. 2001, 59-60, 593-609, DOI: 10.2516/ogst. 2004043.

[3] DAMODHARAN, D., SATHIYAGNANAM, A., RANA, $P$., et al. Combined influence of injection timing and EGR on combustion, performance and emissions of DI diesel engine fueled with neat waste plastic oil. Energy Convers. Manag. 2018, 161, 294-305, DOI: 10.1016/j.enconman. 2018.01.045.

[4] DEEP, A., SANDHU, S.S., CHANDER, S. Experimental investigations on the influence of fuel injection timing and pressure on single cylinder C.I. engine fueled with $20 \%$ blend of castor biodiesel in diesel. Fuel. 2017, 210, 15-22, DOI: 10.1016/j.fuel.2017.08.023.

[5] DUKOWICZ, J.K. Quasi-steady droplet change in the presence of convection. Informal Report Los Alamos Scientific Laboratory. LA7997-MS, 1979.

[6] FUSHUI, L., LEI, Z., BAIGANG, S. et al. Validation and modification of WAVE spray model for diesel combustion simulation. Fuel. 2008, 87(15-16), 3420-3427, DOI: 10.1016/j.fuel.2008.05.001.

[7] HIRKUDE, J., BELOKAR, V., RANDHIR, J. Effect of compression ratio, injection pressure and injection timing on performance and smoke emissions of ci engine fuelled with waste fried oil methyl esters-diesel blend. Mater. Today Proc. 2018, 5(1), 1563-1570, DOI: 10.1016/j.matpr.2017. 11.247.

[8] HOW, H.G., MASJUKI, H.H., KALAM, M.A. et al. Influence of injection timing and split injection strategies on performance, emissions, and combustion characteristics of diesel engine fueled with biodiesel blended fuels. Fuel. 2018, 213, 106-114, DOI: 10.1016/j.fuel.2017.10.102.

[9] JIAQIANG, E. Effects of injection timing and injection pressure on performance and exhaust emissions of a common rail diesel engine fueled by various concentrations of fish-oil biodiesel blends. Energy. 2018, 149, 979-989, DOI: 10.1016/j.energy.2018.02.053.

[10] KASHYAP CHOWDARY, P., GANJI, P.R., SENTHIL KUMAR, M. et al. Numerical analysis of C.I engine to control emissions using exhaust gas recirculation and advanced start of injection. Alexandria Eng. J. 2016, 55(2), 18811891, DOI: 10.1016/j.aej.2016.03.008.
[11] KIM, H.J., PARK, S.H., LEE, C.S. Impact of fuel spray angles and injection timing on the combustion and emission characteristics of a high-speed diesel engine. Energy. 2016, 107, 572-579, DOI: 10.1016/j.energy.2016.04.035.

[12] KOOK, S., PARK, S., BAE, C. Influence of early fuel injection timings on premixing and combustion in a diesel engine. Energy and Fuels. 2008, 22(1), 331-337, DOI: 10.1021/ef700521b.

[13] KOWALSKI, J. The influence of the fuel spray nozzle geometry on the exhaust gas composition from the marine 4-stroke diesel engine. Combustion Engines. 2018, 172(1), 59-63, DOI: 10.19206/ce-2018-107.

[14] KOWALSKI, J. The model of combustion process in the marine 4-stroke engine for exhaust gas composition assessment. Combustion Engines. 2016, 165(2), 60-69, DOI: 10.19206/CE-2016-208.

[15] MA, Z., HUANG, Z., LI, C. Effects of fuel injection timing on combustion and emission characteristics of a diesel engine fueled with diesel-propane blends. Energy \& Fuels. 2007, 21(3), 1504-1510, DOI: 10.1021/ef060574a.

[16] RAKOPOULOS, C.D., RAKOPOULOS, D.C., MAVROPOULOS, G.C. et al. Investigating the EGR rate and temperature impact on diesel engine combustion and emissions under various injection timings and loads by comprehensive two-zone modeling. Energy. 2018, 157, 990-1014, DOI: 10.1016/j.energy.2018.05.178.

[17] SAYIN, C., GUMUS, M., CANAKCI, M. Effect of fuel injection timing on the emissions of a direct-injection (DI) Diesel engine fueled with canola oil methyl ester-diesel fuel blends. Energy \& Fuels. 2010, 24(4), 2675-2682, DOI: 10.1021/ef901451n.

[18] SZYMKOWICZ, P., BENAJES, J. Single-cylinder engine evaluation of multi-component diesel surrogate fuel at a part-load operating condition with conventional combustion. Fuel. 2018, 226, 286-297, DOI: 10.1016/j.fuel.2018.03.157.

[19] TAMILSELVAN, R., RAMESHBABU, R., THIRUNAVUKKARASU, R. et al. Effect of fuel injection timing on performance and emission characteristics of ceiba pentandra biodiesel. Mater. Today Proc. 2018, 5(2), 6770-6779,

[20] WAKISAKA, T. Numerical prediction of mixture formation and combustion processes in premixed compression ignition engines. COMODIA. 2001, 426.

[21] YOUSEFI, A., BIROUK, M., GUO, H. An experimental and numerical study of the effect of diesel injection timing on natural gas/diesel dual-fuel combustion at low load. Fuel. 2017, 203, 642-657, DOI: 10.1016/j.fuel.2017.05.009.

Jerzy Kowalski, DSc., DEng. - Faculty of Ocean Engineering and Ship Technology, Gdansk University of Technology.

e-mail: jerzy.kowalski@pg.edu.pl 